\title{
Thresholds of riparian forest use by terrestrial mammals in a fragmented Amazonian deforestation frontier
}

\author{
Barbara Zimbres $^{1,3}$ Carlos A. Peres $^{2}$ Gabriel Penido ${ }^{1} \cdot$ Ricardo B. Machado $^{1}$
}

\begin{abstract}
Species persistence in fragmented landscapes is intimately related to the quality, structure, and context of remaining habitat remnants. Riparian vegetation is legally protected within private landholdings in Brazil, so we quantitatively assessed occupancy patterns of terrestrial mammals in these remnants, examining under which circumstances different species effectively use them. We selected 38 riparian forest patches and five comparable riparian sites within continuous forest, at which we installed four to five cameratraps per site (199 camera-trap stations). Terrestrial mammal assemblages were sampled for 60 days per station during the dry seasons of 2013 and 2014. We modelled species occupancy and detection probabilities within riparian forest remnants, and examined the effects of patch size, habitat quality, and landscape structure on occupancy probabilities. We then scaled-up modelled occupancies to all 1915 riparian patches throughout the study region to identify which remnants retain the greatest potential to work as habitat for terrestrial vertebrates. Of the ten species for which occupancy was modelled, six responded to forest quality (remnant degradation, cattle intrusion, palm aggregations, and understorey density) or structure (remnant width, isolation, length, and area of the patch from which it originates). Patch suitability was lower considering habitat quality than landscape
\end{abstract}

\footnotetext{
${ }^{1}$ Departamento de Zoologia, Instituto de Ciências Biológicas, Universidade de Brasília, Brasília 70910-900, Brazil

${ }^{2}$ School of Environmental Sciences, Norwich Research Park, University of East Anglia, Norwich NR4 7TJ, UK
}

${ }^{3}$ SHIN QL 11 conjunto 6 casa 11, Brasília, DF 71515-765, Brazil 
structure, and virtually all riparian remnants were unsuitable to maintain a high occupancy probability for all species that responded to forest patch quality or structure. Beyond safeguarding legal compliance concerning riparian remnant amount, ensuring terrestrial vertebrate persistence in fragmented landscapes will require curbing the drivers of forest degradation within private landholdings.

Keywords Community ecology $\cdot$ Corridor $\cdot$ Habitat degradation $\cdot$ Landscape connectivity · Occupancy

\section{Introduction}

The association between habitat amount and patterns of species richness is described by the species-area relationship, one of the strongest tenets of conservation ecology (Preston 1962; MacArthur and Wilson 1967). However, the persistence of any given species in highly fragmented landscapes will depend on both habitat amount and connectivity (Noss 1987; Haddad \& Tewksbury 2005). Classic studies on landscape connectivity have addressed the difference between structural and functional connectivity, whereby habitat patches may be disconnected and individually isolated in the landscape (low structural connectivity) but may be reached by a species, depending on its gap-crossing ability and matrix tolerance (high functional connectivity). The opposite may also be true, whereby a structurally connected landscape does not adequately safeguard dispersal for any given species, depending on the circumstances in which it travels through these elements (Beier and Noss 1998). Measuring landscape connectivity is therefore not straightforward, and ultimately depends on the organism in question (Wiens 1989; Beier and Loe 1992; Taylor et al. 1993; Uezu et al. 2005; Tracey 2006). This idiosyncrasy complicates connectivity studies and the definition of management strategies that can serve a large group of species within a single landscape (Harrison 1992).

It has been suggested that conservation strategies must be designed according to the requirements of those species that are most sensitive to the process of fragmentation, but measuring this 'sensitivity' is not straightforward. Ecological and morphological traits have been related to a species' responses to anthropogenic impacts, but this approach has often failed to explain observed idiosyncrasies (Henle et al. 2004). More likely, the degree to which a species is sensitive to habitat fragmentation will be associated with how it responds to edge-dominated habitats and its degree of matrix tolerance (Lidicker 1999). The contribution of remnant forest patches to serve both as available habitat and promote landscape connectivity will thus be intimately related to ecological responses to modified habitats.

Linear riparian remnants are widespread over tropical landscapes dominated by human activities, but these remnants are frequently too narrow and therefore highly vulnerable to the intrusion of external disturbances from the dominant matrix (Hobbs 1992; Hilty et al. 2006). Patch- and landscape-scale factors will affect the role of these riparian remnants to harbour biodiversity, including their width, length, continuity (Lindenmayer and Nix 1993; Haddad 1999; Hilty et al. 2006; Tubelis et al. 2007; Hawes et al. 2008), vegetation quality (Harrison 1992; Bennett et al. 1994; Lees and Peres 2008), isolation in the landscape (Saunders et al. 1991; Prist et al. 2012), and the type and intensity of disturbance intrusion from the adjacent matrix (Beier and Noss 1998; Gascon et al. 1999; Umetsu et al. 2008). 
In Brazil, environmental legislation requires a minimum riparian forest set-aside to be retained along all perennial streams/rivers within private landholdings, known as Permanent Protection Areas (APPs). Since over half of all natural vegetation throughout the country persists within the $\sim 5.5$ million private landholdings (Sparovek et al. 2015), these APPs remain the best available opportunity to design an integrated riparian remnant network that may serve both as habitat and connectors across entire landscapes at both local and regional scales. Riparian zones are important biodiversity repositories (Hilty et al. 2006; Naiman et al. 1993), and can potentially connect larger remnant forest patches for transient species as well as function as year-round habitats for resident species. Moreover, riparian strips may also act to reduce overall patch isolation in the landscape, benefiting those species exhibiting some degree of gap-crossing ability (Hawes et al. 2008).

The so-called 'arc of deforestation', spanning along the eastern and southern portions of Brazilian Amazonia, is a 1.5 million $\mathrm{km}^{2}$ frontier development region that is ideal to assess the importance of riparian remnants, and investigate their use by forest vertebrates. Deforestation over the last four decades in this region has created extensive fragmented forest landscapes, dominated by cattle pastures and cropland, with varying degrees of forest cover and compliance with environmental legislation (Fearnside 2005). APPs throughout this region are also widely variable in their degree of integrity, in terms of the width, isolation, and forest habitat quality of remaining riparian strips (Lees and Peres 2008).

Empirical evidence of remnant patch use would allow scientists and managers to make assessments and take practical decisions, but the degree to which riparian remnants promote persistence depends on their value as habitat for a myriad of species, and these species' ability to reach the sites. However, an adequate quantitative assessment of their use depends on modelling both occupancy and detection probabilities, since perfect detection is seldom a reality regardless of the survey technique used (MacKenzie et al. 2002). We therefore aim to assess riparian remnant use by different terrestrial mammal species within an occupancy modelling framework to understand the circumstances under which these species effectively use APPs. Specifically, we examined the degree to which use is determined primarily by the patch-structure and internal quality of the remnants or the status of surrounding landscapes. We also performed a scaling-up exercise in which modelled occupancy patterns were extrapolated to the entire study region, in order to identify which riparian remnants provide the greatest opportunities to promote a functionally connected landscape at the regional-scale for the terrestrial mammal community.

\section{Methods}

\section{Study area}

This study covered three neighbouring municipal counties of the northern state of Mato Grosso in southern Brazilian Amazonia: Alta Floresta (09 $\left.53^{\prime} \mathrm{S}, 5^{\circ} 28^{\prime} 725 \mathrm{~W}\right)$, Paranaíta $\left(09^{\circ} 40^{\prime} \mathrm{S}, 56^{\circ} 28^{\prime} \mathrm{W}\right)$, and Carlinda $\left(09^{\circ} 58^{\prime} \mathrm{S}, 55^{\circ} 49^{\prime} \mathrm{W}\right)$. Land use in this $1,620,000$-ha region-located within the Amazon's 'arc of deforestation'-is mainly comprised of cattle ranching in variable-sized landholdings, which were established in the 1980s, so that the anthropogenic matrix around remaining forest patches is broadly similar (Michalski et al. 2008). Currently, the region retains $\sim 53 \%$ of remaining native vegetation, including both upland and seasonally flooded forests. In addition to being highly fragmented, 
the remaining native patches are also subject to high levels of forest degradation, which includes logging activities, cattle intrusion and trampling, and fire (Zimbres et al. 2017).

\section{Study design}

We deployed a set of four to five digital camera traps (Bushnell Trophy Cam ${ }^{\mathrm{TM}}$ and Reconyx HC 500 HyperFire $^{\mathrm{TM}}$ ) at each of 38 riparian forest strips of varying sizes, forest habitat quality, and spatial configuration across the landscape, as well as at five pseudocontrol riparian areas immersed within continuous forest tracts, thus amounting to 43 sampling areas (Fig. 1). Camera traps (CT) were installed 250-300 m apart, amounting to a sample size of $199 \mathrm{CT}$ stations across all sampling sites, and 174 stations considering riparian strips only. Cameras were located along the main axis of the corridor, as close to the water edge as possible. Seven to ten riparian forest sites were sampled simultaneously over a period of 30 days during each field campaign (2013 and 2014). Sampling was only possible during the dry season because a large portion of riparian forests became flooded during the rainy season, between November and April. We thus can infer patterns of habitat use in riparian remnants during the dry season only, when water bodies likely become a more attractive resource. CTs were translocated into new sites, until all 43 sites had been sampled over a period of five months (May-October) during each dry season. This was repeated in the subsequent year, changing the sequential order of all sites sampled, so that sites sampled at the beginning or at the end of the dry season in 2013 were sampled at

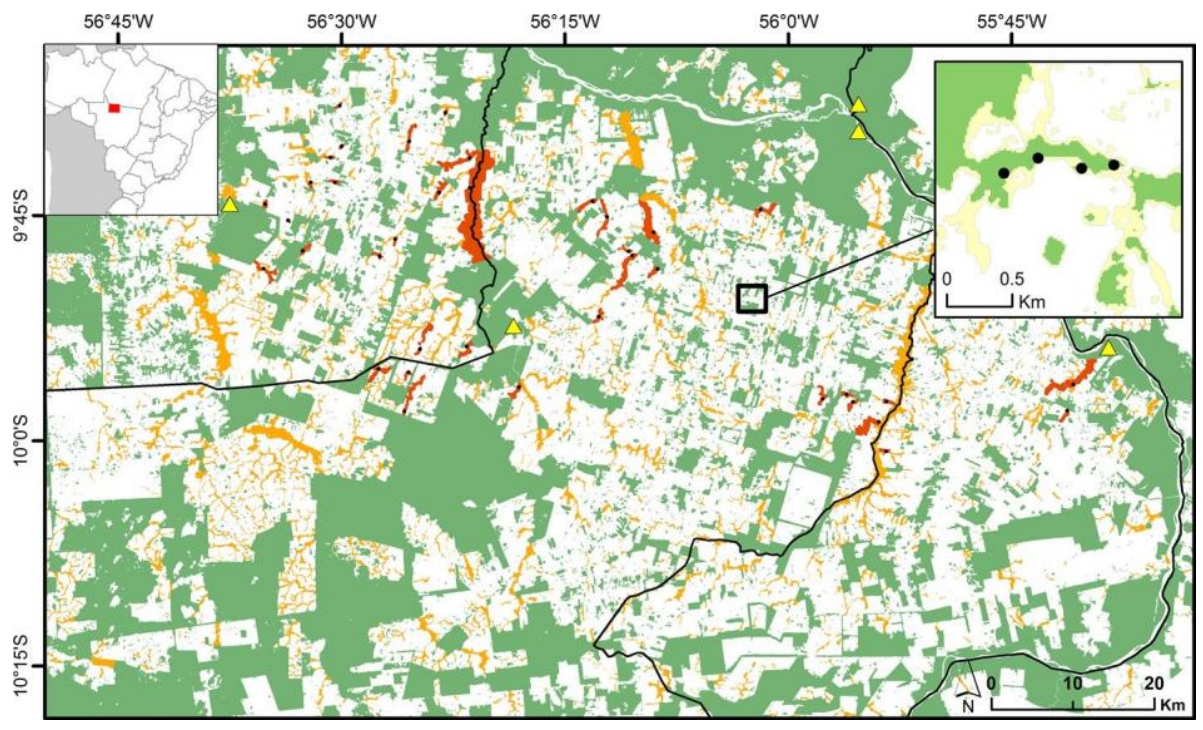

Fig. 1 Study area in the northern Amazonian state of Mato Grosso, Brazil, showing all 38 remnant riparian forest sites surveyed (red polygons), all other riparian forest strips identified (orange polygons), and pseudo-control riparian forests within continuous forest areas (yellow triangles). Insert map at the top right corner illustrates the camera trap stations installed within a riparian corridor, and the two different forest land cover classes obtained using a supervised classification of RapidEye ${ }^{\odot}$ images: mature closed-canopy forest (in green), and degraded forest (yellow). White background indicates nonforest areas consisting primarily of bovine cattle pastures, and dark line indicates the boundaries of the municipal counties. (Color figure online) 
the peak of the dry season in 2014, and vice versa. We baited all CT stations with pierced sardine cans, fixed on poles or trees $2 \mathrm{~m}$ in front of the cameras. Because of occasional episodes of camera malfunction and theft, the sampling effort per camera varied between stations (i.e. could be lower than the maximum of 60 days per station), but this was subsequently taken into account in the analyses.

\section{Environmental variables}

A mosaic of RapidEye $($ ) scenes, with a 15-m resolution from the years 2011-2013, was obtained from the Brazilian Environment Ministry, and used to distinguish five landscape classes using a supervised classification approach: (1) closed-canopy forest; (2) open-canopy forest (interpreted as degraded or secondary forest); (3) shrubby vegetation; (4) cattle pasture; (5) and eucalyptus/teak plantations. From the classified map, we generated four structural variables, either at the patch or the landscape scale, associated with each riparian remnant surveyed: (1) mean width (W, m); (2) non-linear distance (DIST) to nearest source patch (m); (3) source patch size (SS, ha); and (4) total proportion of forest (FP) around the corridor. W consisted of the average length of the transverse section of the riparian strip across all CT stations. It represents the typical width of each sampled riparian forest remnant, which did not vary greatly along the same remnant. DIST consisted of the non-linear distance to the source patch from the centre of the CT line, measured manually over the classified landscape. Source patches were defined and isolated in the landscape using the following steps: all patches structurally connected to our riparian remnants were selected; their core areas were generated using a 100-m inward buffer from the patch edge; these core areas were buffered outward at the same distance; and the final patch area was calculated. This procedure produced isolated patches, excluding narrow protrusions and connections, and were considered the source patches at which riparian strips originated. Finally, a measure of riparian strip isolation in the landscape (FP) was calculated using the following procedure: a 1-km buffer was generated around each riparian remnant, along the camera-trap line (the buffer originated at the edge of the remnant, thus excluding the riparian forest area); and the total proportion of forest (forest classes 1 and 2) within these buffers was calculated. Satellite imagery classification was performed using the ENVI 5.0 software, and measurements and extraction of spatial variables were conducted in ArcGIS 10.2.2 (ESRI 2015).

Four in situ forest patch metrics describing the quality of the vegetation were also obtained at each CT station: (1) understorey density (UD); (2) Mauritia flexuosa palm count (MAU); (3) bovine cattle intrusion (CAT); and (4) proportion of degraded forest (class 2) within a 50-m radial buffer around each CT station (DEG). UD was obtained by counting the number of $10-\mathrm{cm}$ segments that were entirely visible on a $200-\mathrm{cm}$ pole at a distance of $10 \mathrm{~m}$ and $20 \mathrm{~m}$ on either side of each CT station, and then transforming this count into a proportion. MAU was obtained by counting the number of arborescent Mauritia palms visible from a distance of $60 \mathrm{~m}$ from the edge of the corridor, and within a $100-\mathrm{m}$ corridor segment centred at the CT station. Mauritia palm aggregations are distinctive forest features, as they are restricted to permanently waterlogged riparian habitats, and provide a food source for many terrestrial mammal species. CAT was quantitatively assessed within a 30-m radial area around each CT station by ranking the degree of visible cattle intrusion within the forest, based on sightings of cattle signs (tracks and dung) and/or cattle, clear signs of vegetation trampling, stream bank erosion, and presence of wired fences restricting cattle access. This five-graded rank was then summarized as following: (0) no evidence of cattle trampling; (1) rare; (2) occasional; (3) frequent; and (4) very intensive. 


\section{Occupancy modelling}

We conducted single-season occupancy analyses to model riparian forest use by each species. In occupancy analyses, the detection probability (observational process, p) is modelled first, thereby discounting the effect of imperfect detection on the occupancy (or use) probability ( $\Psi$ ), which is the ecological process of interest (MacKenzie et al. 2006). The method assumes closure, which means that occupancy probabilities do not change during the study period. We combined data from the 2 years of study, since we did not expect occupancy patterns to change from year to year, and we defined a sampling occasion as a 7-day week, since some of the species were captured at a high rate during the first few consecutive days after the first detection, indicating that records were not independent within this time period. Therefore, the capture history consisted of ten sampling occasions (5 weeks during each year), although the final week was incomplete. Rather than discarding the last few days of sampling to round the occasions to four full weeks, we considered the total sampling effort as an additional covariate in the analysis. Occasions at sites lacking sampling effort during this final week were modelled as missing observations.

Comparisons between mammal use of riparian forest strips and continuous tracts of primary riparian forest were based on observed incidence (proportion of sites occupied) of each species, since the imbalance between the number of sites (38 forest strips and 5 pseudo-control continuous areas) did not allow adequate modelling of occupancy patterns between these two groups. We therefore highlight that our occupancy estimates (observed incidence) likely underestimate real occupancy patterns in continuous forest sites, since detection probability is almost always lower than 1.0. Occupancy within riparian forest strips could be adequately modelled for ten mammal species: capybara (Hydrochaeris hydrochoerus), paca (Cuniculus paca), agouti (Dasyprocta leporina), ninebanded armadillo (Dasypus novemcinctus), lowland tapir (Tapirus terrestris), white-lipped peccary (Tayassu pecari), collared peccary (Pecari tajacu), coati (Nasua nasua), tayra (Eira barbara), and ocelot (Leopardus pardalis).

Therefore, considering riparian remnants only, two sets of analyses were conducted: first we modelled occupancy probability according to all independent variables at the scale of entire patches $(n=38)$. Secondly, in order to assess whether species responses were any different at a finer scale, we tested the four forest quality variables (which varied between CT stations) as determinants of occupancy patterns $(\Psi)$ at the scale of individual CT stations $(\mathrm{n}=163)$. CT-scale models for a wide-ranging species, the white-lipped peccary (Tayassu pecari), did not converge, so fine-scale patterns for this species could not be inferred. Because of the high likelihood of a spatial autocorrelation between camera traps inside each corridor, based on the procedure adopted by Sberze et al. (2010), we applied an auto logistic model similar to that described by Royle and Dorazio (2008) in a Bayesian inference framework using a Markov chain Monte Carlo (MCMC). We modelled a specific variable, $\gamma$ (gamma), as the probability of occupancy of each neighbouring camera trap within the same corridor, estimated by their posterior probabilities (see code in Supplementary Material), and repeated the occupancy modelling including $\gamma$ as a covariate. Spatial autocorrelation was not an issue at the patch-scale for any species, which we verified by means of a spatial correlogram of the predicted occupancies (Moran's I, p>0.05). To model detection probability (p), remnant width (W) and sampling effort were included as covariates at the patch-scale, while remnant width (W), understorey density (UD), and sampling effort were included as covariates at the CT scale. 
We used model-averaged estimates of occupancy and detection probabilities, as well as regression coefficients and their unconditional standard errors, to assess response patterns to predictor variables. Candidate model sets included all additive combinations between the covariates for $\Psi$ and fixed models with constant occupancy and detection probabilities across sites. All variables were standardized, and the variables DEG, W, DIST, and SS were log-transformed to improve linearity. All models were implemented using WinBUGS in the R2WinBUGS package within the R3.1.2 platform (R Development Core Team 2014). We used vague priors and random initial values for all variables. We ran 3 chains for all models with 20,000 iterations, discarding the first 5000. We checked for convergence visually and through the Gelman-Rubin statistic (Rhat, where values $<1.1$ suggest convergence; Kéry 2010).

\section{Scaling-up projection}

Finally, in order to spatially indicate the patterns of riparian patch suitability across the study landscape, we modelled estimates of occupancy probability obtained from the modelaveraging procedure to all 1915 other remnant riparian forests across the entire 1,620,000ha study area spanning three municipal counties of northern Mato Grosso. Riparian remnants were manually identified, based on the $15-\mathrm{m}$ resolution classified land cover, and putative sampling points ( $N=2-5$ per remnant, depending on riparian patch length) were assigned to each isolated patch in a way that matched our empirical sampling. Three variables that are easily derived from a remote-sensing approach could be extracted using this procedure: (1) the mean proportion of degraded forest within a 50-m radial buffer around each sampling point (DEG); (2) remnant width at each sampling point (W), which was then

averaged across each riparian forest strip; and (3) the proportion of forest within a $1-\mathrm{km}$

buffer around the patch (FP). We therefore scaled-up occupancy model projections at the patch-scale for the entire region for all species that responded to mean DEG, W, and/or FP.

Model-averaged equations were used, which included the coefficients for all vari- ables selected, as well as intercept estimates. Because we wanted to extrapolate species' responses to any of the three variables individually, linear coefficients in the general equation for all other variables were set to zero. We subsequently applied a conservative thresh-

old value ( $\Psi=0.70)$ to continuous values of predicted occupancy probabilities for each species, since we were interested in assessing those riparian patches that reliably serve those species. This generated a binary (presence/absence) map for each species and each of the three variables. These binary maps were then aggregated per variable, generating maps

describing the overall 'pseudo-species' richness expected for all riparian forest patches considering both each predictor and all predictors combined. In the latter case, whenever a single species responded to more than one predictor, it was considered to be present only if

its occupancy probability reached the threshold value for all its predictors. All spatial analyses were conducted in ArcGIS 10.2.2 (ESRI 2015).

\section{Results}

\section{Patterns of occupancy}

During 10,441 sampling days, we obtained 4459 independent CT records representing 25 species. Nine-banded armadillo (Dasypus novemcinctus) was by far the most frequently 
observed species, with also the highest incidence in across all sampling areas. Just under half of all recorded species were rare (fewer than 30 records), and at least five species were very rarely recorded (fewer than ten records) (Fig. 2). The observed incidence, also interpreted as the naïve occupancy rate, for all species in both riparian forest strips and continuous forest areas, as well as modelled occupancy probabilities for the ten species within riparian remnants, are shown in Table 1 . Most species presented higher incidence rates in continuous forest areas than in riparian remnants, with the exception of D. novemcinctus, capybaras (Hydrochoerus hydrochaeris), and ocelots (Leopardus pardalis). The former two species are highly tolerant of open areas, likely tolerant to human-induced landscape changes, and were also most frequently found in riparian remnants. Ocelots were also frequently found along riparian strips, and exhibited an incidence rate comparable to those in continuous forests. This felid may be relatively tolerant of forest loss or degradation given the current status of our study landscape, and indeed had a high modelled occupancy probability in the surveyed remnants (Table 1; Fig. 2).

Detection probabilities were less than 1.0 in all cases, and even the species with the highest detection rates (D. novemcinctus) presented a detection probability of 0.47 $(\mathrm{SE}=0.02)$ (Table 1). Detection was highly variable and responded to one or two of the predictors for four species at the patch-scale. Seven species had non-constant detection

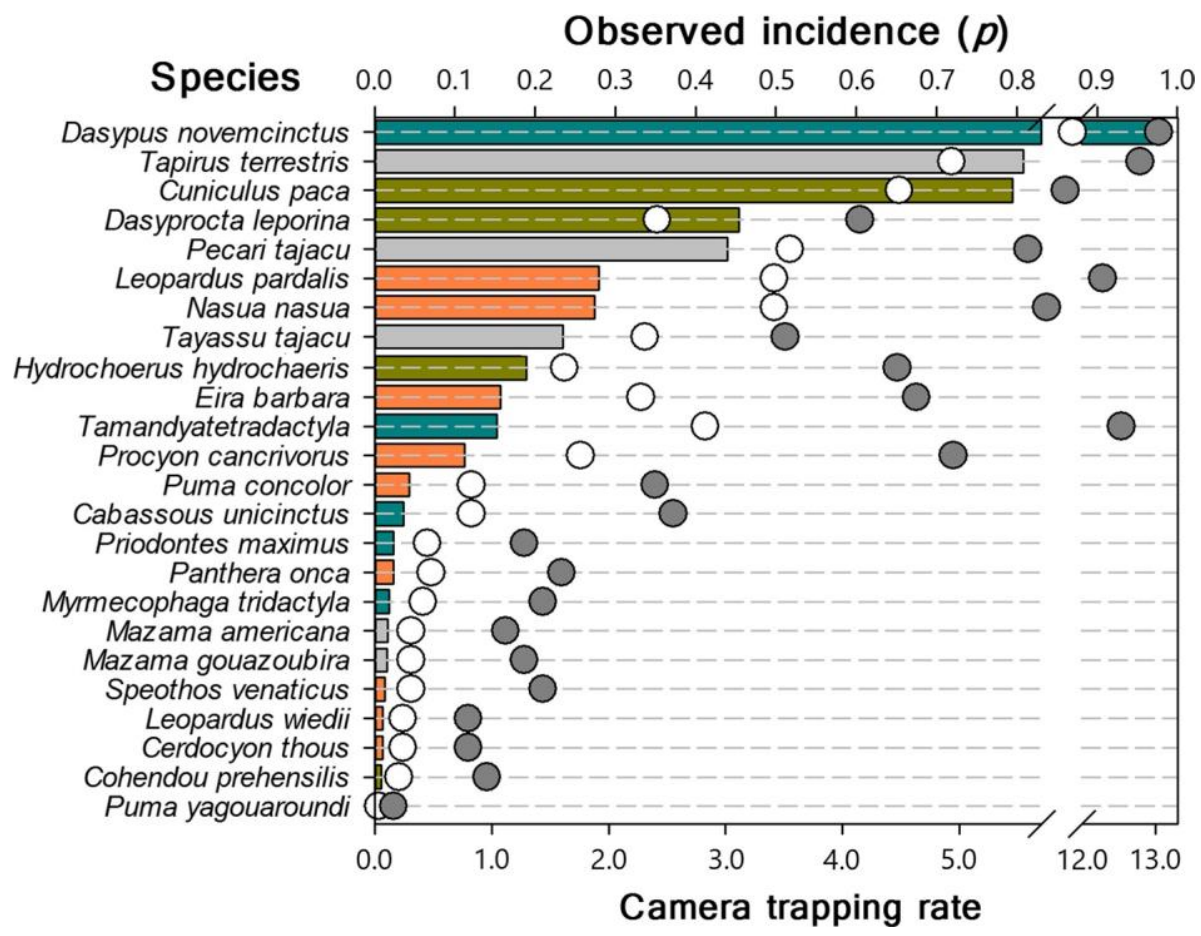

Fig. 2 Overall abundance of 25 terrestrial mammal species across 43 remnant riparian forest corridors sampled in the study region, as measured by camera-trapping rates (independent photo records per 100 camera-trapping nights) in horizontal bars. Observed incidence refers to the proportion of total cameratrap stations (solid circles, $n=199$ ) and riparian forests (shaded circles, $n=43$ ) in which any given species was observed. Horizontal bars are color-coded in terms of mammalian orders: xenarthrans (blue); ungulates (grey); rodents (green); and carnivores (orange). (Color figure online) 
Table 1 Naïve (observed) occupancy patterns of all mammal species recorded by camera trapping across all sampling stations in both remnant riparian forest remnants and riparian zones within continuous forest (CF) areas, as measured by the proportion of sampling areas in which each species was recorded

\begin{tabular}{|c|c|c|c|c|}
\hline \multirow[t]{2}{*}{ Species } & \multicolumn{2}{|c|}{ Naïve occupancy } & \multirow[t]{2}{*}{ Estimated $\Psi$} & \multirow[t]{2}{*}{ Estimated $\mathrm{p}$} \\
\hline & $\mathrm{CF}$ & Remnant & & \\
\hline Tapirus terrestris & 0.92 & 0.68 & $0.83 \pm 0.06$ & $0.25 \pm 0.02$ \\
\hline Nasua nasua & 0.80 & 0.43 & $0.90 \pm 0.11$ & $0.10 \pm 0.01$ \\
\hline Cuniculus paca & 0.76 & 0.63 & $0.75 \pm 0.06$ & $0.30 \pm 0.02$ \\
\hline Pecari tajacu & 0.76 & 0.47 & $0.53 \pm 0.06$ & $0.21 \pm 0.02$ \\
\hline Tayassu pecari & 0.76 & 0.24 & $0.26 \pm 0.08$ & $0.13 \pm 0.02$ \\
\hline Dasyprocta leporina & 0.56 & 0.32 & $0.26 \pm 0.05$ & $0.29 \pm 0.03$ \\
\hline Eira barbara & 0.52 & 0.29 & $0.98 \pm 0.11$ & $0.06 \pm 0.01$ \\
\hline Dasypus novemcinctus & 0.40 & 0.93 & $0.96 \pm 0.02$ & $0.47 \pm 0.02$ \\
\hline Hydrochaeris hydrochoerus & 0.12 & 0.25 & $0.30 \pm 0.05$ & $0.18 \pm 0.02$ \\
\hline Leopardus pardalis & 0.48 & 0.50 & $0.91 \pm 0.05$ & $0.29 \pm 0.03$ \\
\hline Puma concolor & 0.44 & 0.07 & - & - \\
\hline Tamandua tetradactyla & 0.44 & 0.41 & - & - \\
\hline Procyon cancrivorus & 0.28 & 0.25 & - & - \\
\hline Cerdocyon thous & 0.20 & 0.01 & - & - \\
\hline Mazama sp & 0.20 & 0.02 & - & - \\
\hline Panthera onca & 0.20 & 0.05 & - & - \\
\hline Mazama americana & 0.12 & 0.03 & - & - \\
\hline Myrmecophaga tridactyla & 0.12 & 0.05 & - & - \\
\hline Cabassous unicinctus & 0.08 & 0.13 & - & - \\
\hline Coendou prehensilis & 0.08 & 0.02 & - & - \\
\hline Leopardus wiedii & 0.04 & 0.03 & - & - \\
\hline Priodontes maximus & 0.04 & 0.07 & - & - \\
\hline Speothos venaticus & 0.04 & 0.05 & - & - \\
\hline Herpailurus yagouaroundi & 0.00 & 0.01 & - & - \\
\hline
\end{tabular}

Estimated occupancy $(\Psi)$ and detection probability $(\mathrm{p})( \pm \mathrm{SE})$ are available for only ten species for which occupancy modelling could be implemented. Species are ordered top to bottom according to their naïve occupancy rate at $\mathrm{CF}$ sites

probabilities at the CT-scale, with Effort being the most important predictor of detection probability (Table 2). Four of the ten species modelled failed to respond to predictors of occupancy probability at either scale, according to regression coefficients: D. novemcinctus, H. hydrochaeris, Tapirus terrestris, and Leopardus pardalis (Table 3).

Predictors at the patch-scale influenced the occupancy probabilities of six of the ten species (Table 3, Fig. 3). Influential predictors are largely the same at both the CTand the patch-scale, except for $N$. nasua, which responded to understorey density and Mauritia counts at the CT-scale (Fig. 4e, f), and only riparian strip width at the patchscale (W), seemingly reaching an asymptotic pattern in remnants wider than $\sim 220 \mathrm{~m}$ (Fig. 3g). The overall proportion of remnant forest around each riparian strip had a positive effect on the occupancy probabilities of both collared and white-lipped peccaries (Fig. 3b, j), with an apparent threshold for P. tajacu of $30 \%$ below which its occupancy probability dropped sharply. Proportion of surrounding forests had a counter-intuitive 
Table 2 Model-averaged regression coefficients (and 95\% confidence intervals) for all variables tested to influence detection probability (p) of the mammal species examined at both the patch- and the CT-scale

\begin{tabular}{|c|c|c|c|c|}
\hline & Intercept & UNDER & $\mathrm{EFF}$ & $\mathrm{W}$ \\
\hline \multicolumn{5}{|l|}{ Patch-scale } \\
\hline Cuniculus paca & $0.18(-0.060 .41)$ & $-0.07(-0.280 .15)$ & $0.22(0.000 .44)$ & $0.22(-0.030 .50)$ \\
\hline Dasyprocta leporina & $-0.04(-0.350 .26)$ & $0.19\left(\begin{array}{lll}-0.11 & 0.49)\end{array}\right.$ & $-0.08(-0.460 .33)$ & $0.04(-0.220 .31)$ \\
\hline Dasypus novemcinctus & $1.29(1.041 .55)$ & $-0.01(-0.260 .25)$ & $0.08(-0.160 .33)$ & $-0.19(-0.440 .05)$ \\
\hline Eira barbara & $-1.22(-1.56-0.89)$ & $0.19(-0.150 .52)$ & $0.08(-0.290 .42)$ & $0.05(-0.250 .33)$ \\
\hline Hydrochoerus hydrochaerys & $-1.26(-1.55-0.98)$ & $0.10(-0.170 .35)$ & $0.39(0.100 .68)$ & $-0.07\left[\begin{array}{lll}-0.45 & 0.30)\end{array}\right.$ \\
\hline Leopardus pardalis & $-2.31(-2.54-2.05)$ & $-0.09(-0.350 .14)$ & $0.12(-0.120 .36)$ & $0.18(-0.060 .41)$ \\
\hline Nasua nasua & $-1.08(-1.36-0.81)$ & $-0.41(-0.70-0.12)$ & $0.05(-0.210 .31)$ & $0.05(-0.240 .34)$ \\
\hline Pecari tajacu & $-0.49(-0.75-0.22)$ & $-0.10(-0.340 .14)$ & $0.12(-0.130 .36)$ & $0.43(0.190 .69)$ \\
\hline Tapirus terrestris & $0.05(-0.180 .27)$ & $-0.03(-0.240 .19)$ & $0.37(0.140 .61)$ & $-0.22(-0.440 .00)$ \\
\hline Tayassu pecari & $-1.24(-1.66-0.83)$ & $0.10(-0.290 .49)$ & $0.04(-0.430 .48)$ & $-0.09(-0.430 .26)$ \\
\hline \multicolumn{5}{|l|}{ CT-scale } \\
\hline Cuniculus paca & $-0.92(-1.09-0.75)$ & $-0.06(-0.210 .10)$ & $0.25(0.040 .47)$ & - \\
\hline Dasyprocta leporina & $-1.01(-1.32-0.73)$ & $0.18(-0.050 .41)$ & $0.89(0.441 .41)$ & - \\
\hline Dasypus novemcinctus & $-0.14(-0.26-0.02)$ & $-0.08(-0.200 .03]$ & $0.21(0.040 .38)$ & - \\
\hline Eira barbara & $-3.00(-3.37-2.62)$ & $-0.01(-0.340 .31)$ & $0.50(0.051 .05)$ & - \\
\hline Hydrochoerus hydrochaerys & $-1.58(-1.95-1.25)$ & $0.19(-0.100 .48)$ & $0.03(-0.340 .41)$ & - \\
\hline Leopardus pardalis & $-2.31(-2.54-2.05)$ & $-0.09(-0.350 .14)$ & $0.15(-0.090 .42)$ & - \\
\hline Nasua nasua & $-2.48(-2.72-2.24)$ & $-0.38(-0.63-0.12)$ & $0.18(-0.120 .53)$ & - \\
\hline Pecari tajacu & $-1.19(-1.44-0.96)$ & $-0.10(-0.320 .13)$ & $-0.35(-0.67-0.03)$ & - \\
\hline Tapirus terrestris & $-1.14(-1.33-0.95)$ & $-0.21(-0.36-0.05)$ & $0.25(0.010 .49)$ & - \\
\hline Tayassu pecari & - & - & - & - \\
\hline
\end{tabular}

Predictor coefficients found to be influential are highlighted in bold (except Intercept)

$U N D E R$ understorey density, $E F F$ sampling effort (trap.days), $W$ riparian strip width (m)

*Log-transformed variables 
Table 3 Model-averaged regression coefficients (and 95\% confidence intervals) for all variables tested to influence occupancy probability (p) of the mammal species examined at both the patch- and the CT-scale

\begin{tabular}{|c|c|c|c|c|c|c|c|c|c|c|}
\hline & Intercept & $\mathrm{DEG}^{*}$ & CAT* $^{*}$ & UNDER* & MAU* & $\mathrm{W}^{*}$ & DIST* $^{*}$ & FP* & $\mathrm{SS}^{*}$ & Gamma \\
\hline \multicolumn{11}{|l|}{ Patch-scale } \\
\hline C. paca & 7.75 (3.89 12.47) & $\begin{array}{r}-4.33 \\
(-8.05 \\
-1.01)\end{array}$ & $\begin{array}{l}2.17(-1.85 \\
5.94)\end{array}$ & $\begin{array}{l}0.47(-2.14 \\
3.10)\end{array}$ & $\begin{array}{r}-4.97 \\
(-9.17 \\
-2.06)\end{array}$ & $\begin{array}{l}-0.28 \\
\quad(-3.71 \\
2.93)\end{array}$ & $\begin{array}{l}0.81(-2.58 \\
\quad 3.87)\end{array}$ & $\begin{array}{l}1.23(-1.88 \\
4.43)\end{array}$ & $\begin{array}{l}-0.74 \\
\quad(-4.33 \\
2.42)\end{array}$ & - \\
\hline D. leporina 1 & $\begin{array}{c}.07(-0.09 \\
2.85)\end{array}$ & $\begin{aligned}- & 0.48 \\
& (-2.18 \\
& 0.95)\end{aligned}$ & $\begin{array}{l}-2.50 \\
(-5.65 \\
-0.54)\end{array}$ & $\begin{aligned}- & 1.37 \\
& (-3.52 \\
& 0.29)\end{aligned}$ & $\begin{aligned}- & 0.62 \\
& (-2.14 \\
& 0.64)\end{aligned}$ & $\begin{array}{l}0.85(-0.69 \\
2.75)\end{array}$ & $\begin{array}{l}1.21(-0.29 \\
3.38)\end{array}$ & $\begin{array}{l}-0.84 \\
\quad(-2.51 \\
0.49)\end{array}$ & $\begin{array}{l}-0.03-1.20 \\
1.19)\end{array}$ & \\
\hline $\begin{array}{l}\text { D. novemci- } \\
\quad \text { nctus }\end{array}$ & $\begin{array}{c}11.75(6.88 \\
17.38))\end{array}$ & $\begin{aligned}- & 0.28 \\
& (-5.04 \\
& 4.54)\end{aligned}$ & $\begin{aligned}- & 0.23 \\
& (-4.85 \\
& 4.52)\end{aligned}$ & $\begin{aligned}- & 0.64 \\
& (-5.07 \\
& 4.22)\end{aligned}$ & $\begin{array}{l}0.71(-3.47 \\
6.14)\end{array}$ & $\begin{array}{l}0.13(-4.41 \\
5.05)\end{array}$ & $\begin{array}{l}0.16(-4.38 \\
\quad 4.72)\end{array}$ & $\begin{array}{l}0.13(-4.20 \\
4.85)\end{array}$ & $\begin{array}{l}0.33(-3.91 \\
5.12)\end{array}$ & - \\
\hline E. barbara & \multicolumn{2}{|c|}{ 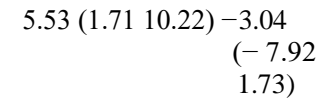 } & $\begin{array}{l}1.69(-2.77 \\
6.76)\end{array}$ & $\begin{aligned}- & 2.50 \\
& (-6.19 \\
& 0.90)\end{aligned}$ & $\begin{array}{c}-6.54 \\
(-11.88 \\
-2.01)\end{array}$ & $\begin{array}{l}1.43(-2.60 \\
6.38)\end{array}$ & $\begin{array}{l}3.23(-1.17 \\
7.48)\end{array}$ & $\begin{array}{r}-4.21 \\
(-8.00 \\
-0.86)\end{array}$ & $\begin{array}{l}1.44(-3.02 \\
8.11)\end{array}$ & - \\
\hline $\begin{array}{l}\text { H. hydro- } \\
\text { chaerys }\end{array}$ & \multicolumn{2}{|c|}{  } & $\begin{aligned}- & 0.33 \\
& (-5.80 \\
& 5.41)\end{aligned}$ & $\begin{aligned}- & 0.55 \\
& (-4.47 \\
& 3.69)\end{aligned}$ & $\begin{aligned}- & 4.27 \\
& (-8.87 \\
& 0.29)\end{aligned}$ & $\begin{aligned}- & 1.48 \\
& (-7.56 \\
& 6.16)\end{aligned}$ & $\begin{aligned}- & 2.11 \\
& (-6.66 \\
& 2.08)\end{aligned}$ & $\begin{aligned}- & 0.54 \\
& (-5.22 \\
& 3.95)\end{aligned}$ & $\begin{aligned}- & 2.18 \\
& (-6.96 \\
& 2.50)\end{aligned}$ & - \\
\hline L. pardalis & $\begin{array}{c}10.51(5.72 \\
16.14)\end{array}$ & $\begin{aligned}- & 1.16 \\
& (-5.56 \\
& 3.02)\end{aligned}$ & $\begin{array}{l}0.36(-4.10 \\
5.37)\end{array}$ & $\begin{aligned}- & 1.15 \\
& (-5.37 \\
& 3.72)\end{aligned}$ & $\begin{aligned}- & 1.99 \\
& (-6.07 \\
& 3.40)\end{aligned}$ & $\begin{aligned}- & 0.73 \\
& (-4.70 \\
& 3.84)\end{aligned}$ & $\begin{array}{l}0.43(-4.37 \\
4.57)\end{array}$ & $\begin{aligned}- & 1.02 \\
& (-6.82 \\
& 5.28)\end{aligned}$ & $\begin{array}{l}2.23(-2.01 \\
7.21)\end{array}$ & - \\
\hline N. nasua & $9.91(5.46$ 15.2) & $\begin{array}{l}-0.71 \\
(-3.99 \\
2.25)\end{array}$ & $\begin{aligned}- & 2.58 \\
& (-6.20 \\
& 0.81)\end{aligned}$ & $\begin{array}{l}1.02(-2.98 \\
5.56)\end{array}$ & $\begin{aligned}- & 1.36 \\
& (-3.76 \\
& 1.01)\end{aligned}$ & $\begin{array}{l}5.35(1.09 \\
10.05)\end{array}$ & $\begin{array}{l}1.04(-3.69 \\
5.66)\end{array}$ & $\begin{array}{l}3.01(-0.63 \\
7.01)\end{array}$ & $\begin{array}{l}-0.54 \\
\quad(-4.04 \\
3.24)\end{array}$ & - \\
\hline P. tajacu & $6.92(2.97$ 12.27) & $\begin{array}{l}-2.81 \\
(-6.19 \\
-0.05)\end{array}$ & $\begin{array}{l}-2.69 \\
(-6.12 \\
0.51)\end{array}$ & $\begin{array}{l}-1.62 \\
(-4.47 \\
1.16)\end{array}$ & $\begin{array}{l}-1.69 \\
\quad(-4.67 \\
0.53)\end{array}$ & $\begin{aligned}- & 0.37 \\
& (-3.74 \\
& 2.52)\end{aligned}$ & $\begin{array}{l}0.07(-3.58 \\
3.43)\end{array}$ & $\begin{array}{l}4.37(1.22 \\
8.59)\end{array}$ & $\begin{array}{l}0.98(-1.7 \\
4.34)\end{array}$ & - \\
\hline \multicolumn{3}{|c|}{$\begin{aligned} & \text { T. terrestris } 8.58 \text { (4.16 15.67) - } 2.26 \\
&(-5.98 \\
&1.14)\end{aligned}$} & $\begin{array}{l}0.07(-3.72 \\
5.06)\end{array}$ & $\begin{array}{l}-0.76 \\
(-4.04 \\
2.78)\end{array}$ & $\begin{array}{l}-1.48 \\
\quad(-4.55 \\
0.54)\end{array}$ & $\begin{array}{c}-0.09 \\
(-3.35 \\
3.69)\end{array}$ & $\begin{array}{c}-0.54 \\
(-4.71 \\
3.65)\end{array}$ & $\begin{array}{l}0.75(-2.13 \\
4.27)\end{array}$ & $\begin{array}{l}0.24(-3.25 \\
3.89)\end{array}$ & - \\
\hline
\end{tabular}


Table 3 (continued)

\begin{tabular}{|c|c|c|c|c|c|c|c|c|c|c|}
\hline & Intercept & DEG* & $\mathrm{CAT}^{*}$ & UNDER* & MAU* & $\mathrm{W}^{*}$ & DIST* & FP* & SS* & Gamma \\
\hline T. pecari & $\begin{array}{l}1.71(-0.50 \\
4.47)\end{array}$ & $\begin{array}{c}-3.65 \\
(-7.06 \\
-0.7)\end{array}$ & $\begin{array}{l}-4.79 \\
{[-9.100 .58)}\end{array}$ & $\begin{array}{r}-3.99 \\
(-7.74 \\
-0.01)\end{array}$ & $\begin{array}{c}-1.88 \\
\quad(-5.20 \\
0.99)\end{array}$ & $\begin{array}{c}-0.16 \\
(-4.90 \\
4.03)\end{array}$ & $\begin{array}{l}3.58(0.86 \\
6.77)\end{array}$ & $\begin{array}{c}7.37(2.93 \\
11.87)\end{array}$ & $\begin{array}{c}-1.79 \\
(-5.34 \\
4.07)\end{array}$ & - \\
\hline \multicolumn{11}{|l|}{ CT-scale } \\
\hline C.paca & $\begin{array}{l}-1.44(-2.66 \\
-0.29)\end{array}$ & $\begin{array}{r}-\mathbf{0 . 8 3} \\
(-\mathbf{2 . 2 0} \\
-\mathbf{0 . 0 7})\end{array}$ & $\begin{array}{c}-0.23 \\
\quad(-0.91 \\
0.46)\end{array}$ & $\begin{array}{l}0.38(-0.45 \\
1.17)\end{array}$ & $\begin{array}{r}-0.86 \\
(-1.81 \\
-0.15)\end{array}$ & - & - & - & - & $4.24(2.496 .6)$ \\
\hline D. leporina & $\begin{array}{l}-1.98 \\
\quad(-2.74-1.26)\end{array}$ & $\begin{array}{c}-0.40 \\
(-0.87 \\
0.06)\end{array}$ & $\begin{array}{r}-0.73 \\
(-1.37 \\
-0.15)\end{array}$ & $\begin{array}{l}0.15(-0.38 \\
0.69)\end{array}$ & $\begin{aligned}- & 0.39 \\
& (-1.01 \\
& 0.13)\end{aligned}$ & - & - & - & - & $\begin{array}{l}2.96(1.58 \\
4.38)\end{array}$ \\
\hline $\begin{array}{l}\text { D. novemci- } \\
\text { nctus }\end{array}$ & $\begin{array}{l}3.08(-0.97 \\
7.99)\end{array}$ & $\begin{array}{c}-0.30 \\
(-1.30 \\
0.66)\end{array}$ & $\begin{array}{c}-0.87 \\
(-1.96 \\
0.09)\end{array}$ & $\begin{array}{l}-1.05 \\
\quad(-2.43 \\
0.08)\end{array}$ & $\begin{array}{l}1.88(-0.13 \\
6.61)\end{array}$ & - & - & - & - & $\begin{array}{l}1.30(-3.43 \\
5.49)\end{array}$ \\
\hline E. barbara & $\begin{array}{l}1.31(-3.66 \\
7.85)\end{array}$ & $\begin{array}{c}-0.37 \\
(-4.33 \\
2.95)\end{array}$ & $\begin{array}{c}-0.59 \\
\quad(-4.60 \\
3.33)\end{array}$ & $\begin{array}{c}-0.64 \\
\quad(-5.26 \\
4.08)\end{array}$ & $\begin{array}{l}-5.33 \\
\quad(-10.87 \\
-1.13)\end{array}$ & - & - & - & - & $\begin{array}{l}4.71(-2.58 \\
11.82)\end{array}$ \\
\hline $\begin{array}{l}\text { H. hydro- } \\
\text { chaerys }\end{array}$ & $\begin{array}{l}-1.13(-1.86 \\
-0.34)\end{array}$ & $\begin{array}{c}-0.23 \\
(-0.66 \\
0.19)\end{array}$ & $\begin{array}{c}-0.24 \\
(-0.74 \\
0.26)\end{array}$ & $\begin{array}{c}-0.37 \\
(-0.89 \\
0.12)\end{array}$ & $\begin{array}{c}-0.11 \\
\quad(-0.59 \\
0.32)\end{array}$ & - & - & - & - & $\begin{array}{l}0.92(-0.88 \\
2.62)\end{array}$ \\
\hline L. pardalis & $\begin{array}{l}3.88(-1.59 \\
10.95)\end{array}$ & $\begin{array}{c}-2.27 \\
(-7.57 \\
3.34)\end{array}$ & $\begin{array}{l}2.03(-2.05 \\
7.10)\end{array}$ & $\begin{array}{l}0.05(-4.65 \\
5.91)\end{array}$ & $\begin{array}{c}-0.20 \\
(-2.71 \\
5.57)\end{array}$ & - & - & - & - & $\begin{array}{c}5.58(-0.66 \\
12.16)\end{array}$ \\
\hline N. nasua & $\begin{array}{l}3.17(-1.72 \\
9.07)\end{array}$ & $\begin{array}{r}-2.43 \\
(-5.69 \\
-0.14)\end{array}$ & $\begin{array}{c}-1.09 \\
\quad(-3.38 \\
0.88)\end{array}$ & $\begin{array}{c}3.12(0.09 \\
6.80)\end{array}$ & $\begin{array}{l}-1.50 \\
\quad(-3.64 \\
0.30)\end{array}$ & - & - & - & - & $\begin{array}{l}5.50(-0.13 \\
11.78)\end{array}$ \\
\hline P.tajacu & $\begin{array}{l}-1.05(-1.89 \\
-0.21)\end{array}$ & $\begin{array}{r}-0.67 \\
(-1.21 \\
-0.20)\end{array}$ & $\begin{array}{c}-0.38 \\
(-0.90 \\
0.12)\end{array}$ & $\begin{array}{l}0.09(-0.39 \\
0.59)\end{array}$ & $\begin{array}{c}-0.25 \\
(-0.79 \\
0.21)\end{array}$ & - & - & - & - & $\begin{array}{l}2.19(0.72 \\
3.72)\end{array}$ \\
\hline
\end{tabular}


Table 3 (continued)

\begin{tabular}{|c|c|c|c|c|c|c|c|c|c|c|}
\hline & Intercept & $\mathrm{DEG}^{*}$ & CAT* $^{*}$ & UNDER* & MAU* & $\mathrm{W}^{*}$ & DIST* & $\mathrm{FP}^{*}$ & $\mathrm{SS}^{*}$ & Gamma \\
\hline T. terrestris & $\begin{array}{l}-1.41(-2.69 \\
-0.23)\end{array}$ & $\begin{array}{c}-0.08 \\
(-0.80 \\
0.57)\end{array}$ & $\begin{array}{c}-0.19 \\
(-0.92 \\
0.49)\end{array}$ & $\begin{array}{l}0.12(-0.595 \\
0.91)\end{array}$ & $\begin{array}{c}-0.27 \\
\quad(-0.76 \\
0.23)\end{array}$ & - & - & - & - & $\begin{array}{l}4.16(2.32 \\
6.47)\end{array}$ \\
\hline T. pecari & - & - & - & - & - & - & - & - & - & - \\
\hline
\end{tabular}

The influence of the modelled autocorrelation term (Gamma) is also shown. Predictor coefficients found to be influential are highlighted in bold (except Intercept)

*Log-transformed variables

$D E G$ proportion of degraded forest within a 50-m buffer around each camera trap station, CAT degree of cattle intrusion (0-4), UNDER understorey density, MAU Mauritia flexuosa palm abundance at each sampling site, $W$ riparian strip width (m), DIST non-linear distance to the nearest source patch (m), FP total proportion of forest within a 1 $\mathrm{km}$ buffer around each riparian forest patch, $S S$ size of nearest source patch (ha) 

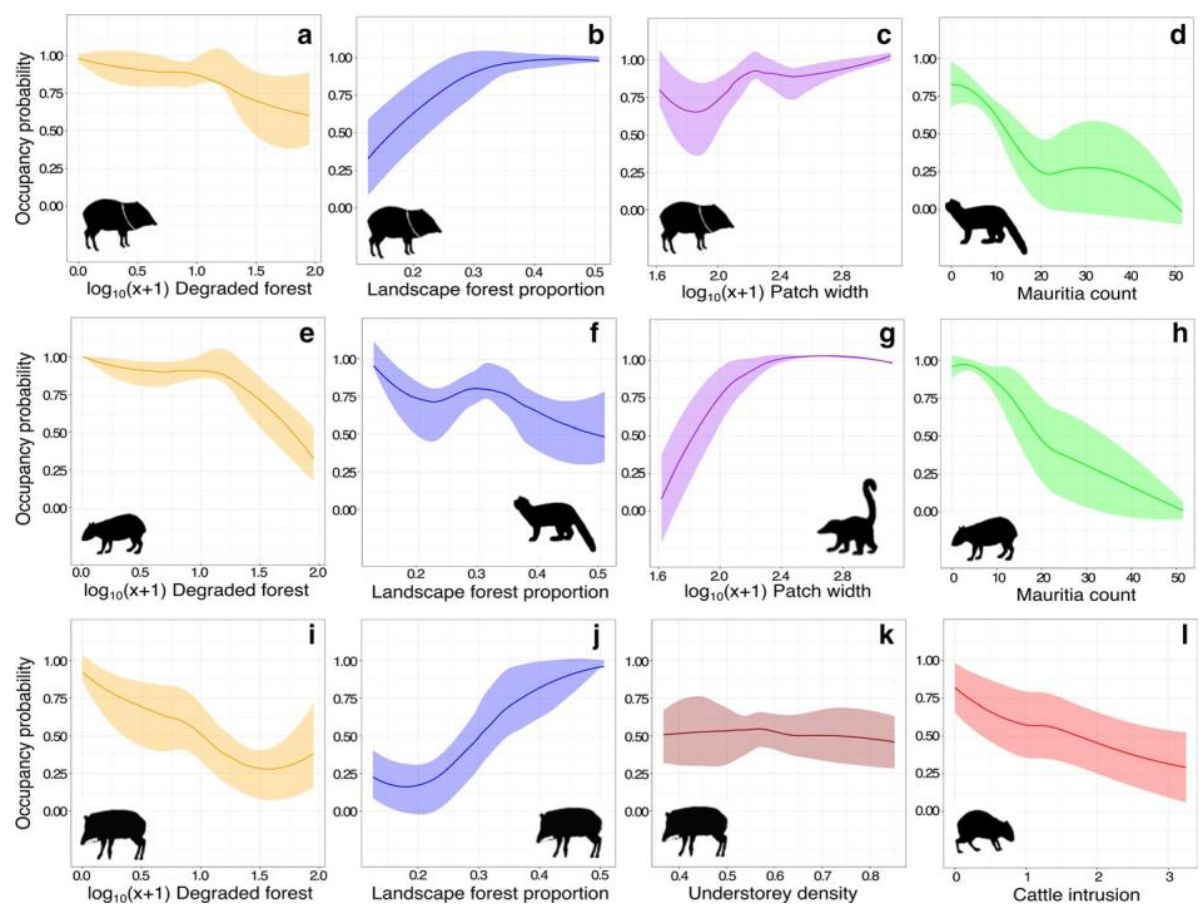

Fig. 3 Patch-scale response curves (and unconditional standard errors) between the terrestrial mammal species occupancy probabilities (a-c: Pecari tajacu; d and f: Eira barbara; e and h: Cuniculus paca; g: Nasua nasua; i-k: Tayassu pecari; l: Dasyprocta leporina) and the variables selected, based on modelaveraged regression estimates (nonlinear functions of the same colour refer to the same predictor variable). Relationships are only presented for predictors that were selected as influential by the model-averaging procedure

negative effect on E. barbara (Fig. 3f). P. tajacu also responded positively to riparian strip width (W; Fig. 3c). D. leporina responded to the same predictor at both the patchand the CT-scale, presenting a lower occupancy probability at sites showing higher cattle intrusion (Figs. 31, 4d). C. paca also responded similarly at both scales, and its occupancy was negatively affected by Mauritia abundance and forest degradation (Figs. 3e, $\mathrm{h}, 4 \mathrm{~b}, \mathrm{c})$. Mean degradation within the patch also had a negative influence on peccaries (Figs. 3a, i, 4a). Mauritia palm aggregations had a negative effect on the occupancy probabilities of E. barbara at both scales (Figs. 3d, 4g). Although not a very strong relationship, mean understorey density (at the patch-scale) was also selected as a predictor of $T$. pecari occupancy probability (Fig. 3k). Distance to the source patch had a counter-intuitive positive effect on $T$. pecari (Table 3 ), this result is likely misleading and caused by a single riparian remnant, which was structurally intact but was sampled at a disproportionately long distance from the source patch $(8.5 \mathrm{~km})$, compared to all other remnants $($ mean $=1 \mathrm{~km}$ ). This patch presented a high number of white-lipped peccary records, and may have biased the relationship, so that we consider this result unreliable. Four species also responded to the spatial autocorrelation term at the CT-scale: $T$. terrestris, P. tajacu, D. leporina, and C. paca (Table 3). 

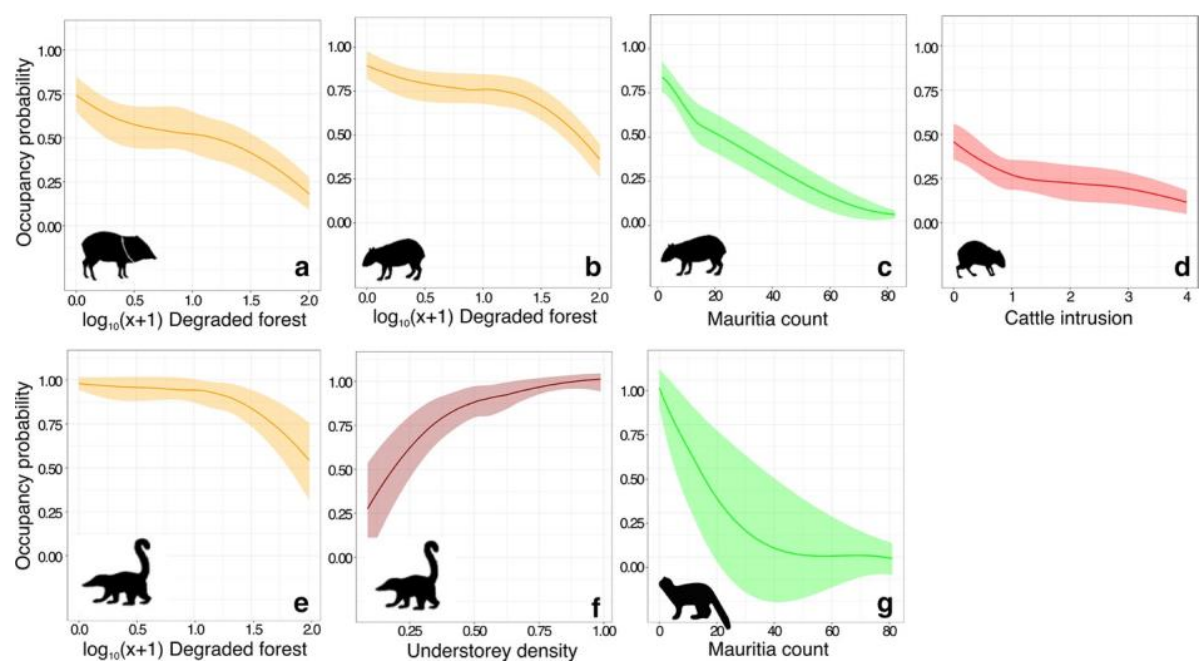

Fig. 4 CT-scale response curves (and unconditional standard errors) between the terrestrial mammal species occupancy probabilities (a: Pecari tajacu; b and f: Cuniculus paca; c and d: Nasua nasua; e: Eira

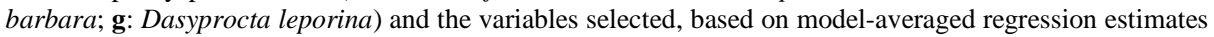
(nonlinear functions of the same colour refer to the same predictor variable). Relationships are only presented for predictors that were selected as influential by the model-averaging procedure

\section{Projected patterns of occupancy}

Across the entire study region, 5053 riparian forest points were generated to describe forest degradation, width, and isolation from 1915 identified forest remnants. The mean proportion of degraded forest within each 50-m buffer around each point was 0.17 $(\mathrm{SD}=0.24)$. Mean riparian forest width was $153 \mathrm{~m}(\mathrm{SD}=93 \mathrm{~m})$, ranging from as narrow as $40 \mathrm{~m}$ to as wide as $1131 \mathrm{~m}$. The total forest cover within the 1-km buffers around each riparian strip ranged between 2 and 91\%, averaging 34\% (SD $=17 \%$ ). Considering forest isolation, represented by the amount of forest surrounding each riparian strip, only $40-50 \%$ of available patches safeguarded a high occupancy probability $(\Psi>0.70)$ of the species (Table 4, Fig. 5). The same is true for patch width for the coati, but almost none of the available patches presented an occupancy probability above the threshold for collared peccary (Table 4). Degradation patterns were very consistent for the three species, for which nearly half the remnant patches were not suitable to maintain a high occupancy probability (Table 4, Fig. 5). Considering the combined occupancy probability for the two peccaries, which responded to more than one predictor, P. tajacu was nearly absent from all riparian patches $\left(\Psi_{0.70}=0.03\right)$, whereas $T$. pecari had its predicted occupancy probability reduced by half $\left(\Psi_{0.70}=0.26\right)$. Overall, virtually all riparian remnants surveyed were unsuitable to maintain a 0.70 occupancy probability for all five species (Fig. 5). However, we note that our study area was mostly concentrated on the northern portion of the landscape. Estimates for the southernmost portions can therefore be biased and less accurate compared to the northern region, although our modelling is probably robust given that the entire study region was similar in terms of baseline forest structure and human activity. 
Table 4 Mean predicted occupancy probability across the entire study landscape $(n=1915)$ for each species that responded either to patch structure, measured as the total proportion of surrounding forest within a $1-\mathrm{km}$ buffer around each patch (FP) and/or riparian strip width (W), or riparian forest quality, measured as the mean proportion of degraded forest within a 50-m buffer around each sampling point (DEG)

\begin{tabular}{|c|c|c|c|c|c|c|}
\hline \multirow[t]{2}{*}{ Species } & \multicolumn{2}{|l|}{$\mathrm{FP}^{*}$} & \multicolumn{2}{|l|}{$\mathrm{W}^{*}$} & \multicolumn{2}{|l|}{ DEG* } \\
\hline & $\Psi_{\text {mean }}$ & $\Psi_{0.70}$ & $\Psi_{\text {mean }}$ & $\Psi_{0.70}$ & $\Psi_{\text {mean }}$ & $\Psi_{0.70}$ \\
\hline C. paca & - & - & - & - & 0.59 & 0.55 \\
\hline E. barbara & 0.54 & 0.48 & - & - & - & - \\
\hline N. nasua & - & - & 0.47 & 0.40 & - & - \\
\hline P. tajacu & 0.47 & 0.40 & 0.51 & 0.05 & 0.57 & 0.52 \\
\hline T. pecari & 0.46 & 0.41 & - & - & 0.57 & 0.53 \\
\hline
\end{tabular}

The proportions of riparian patches classified as suitable for use by each species, considering a threshold of $\Psi=0.70$ are also presented

*Log-transformed variables

\section{Discussion}

Empirical evidence of animal habitat use comprises the basic information required to assess habitat suitability and plan effective conservation measures. Occupancy modelling is a relatively modern tool that permits estimates of occupancy (or use) probability under conditions of imperfect detection, which is almost always the case in nature (MacKenzie et al. 2002). Our analyses indicate that taking into account species-specific detectability differences is crucial, particularly for those species that are less abundant and/or more sensitive to habitat disturbance, exhibiting non-constant and low detection probabilities. Our observed occupancy rates in riparian areas within continuous forests are therefore likely an underestimation of the real patterns at those sites. Nonetheless, naïve occupancy patterns in these continuous 'pseudo-controls' were systematically greater than those observed along remnant riparian strips, except for two species that are highly tolerant of the wider openhabitat matrix (Eisenberg and Redford 1999) — nine-banded armadillo and capybarawhich clearly indicate a high degree of tolerance to the forest fragmentation process. This was also the case of some of the least recorded species-naked-tale armadillo (Cabassous unicinctus), giant armadillo (Priodontes maximus), bush dog (Speothos venaticus), and jaguarundi cat (Herpailurus yagouaroundi). For these rare species, low number of detections renders occupancy patterns inconclusive.

This study is consistent with idiosyncrasies found in faunal responses to land use change and human-induced disturbances (Wiens 1989; Beier and Loe 1992; Taylor et al. 1993; Uezu et al. 2005; Tracey 2006). Occupancy probability in response to habitat loss and degradation varied widely across species, but does not reflect any expected pattern in relation to trophic level, phylogeny, or body size. For instance, it is suggested that larger and gregarious species are more heavily affected by habitat fragmentation than smaller, solitary species (Henle et al. 2004). In our case, a large-bodied gregarious rodent, the capybara, did not respond to habitat quality or structure, while a smaller-bodied solitary rodent, the agouti, responded to both habitat degradation and cattle intrusion into riparian zones. This pattern, however, may be more related to species habitat specialization, since capybaras are highly tolerant of open habitats. Also, the only carnivore species analysed, the ocelot, was very common along riparian remnants, but did not respond to any of the predictors. 


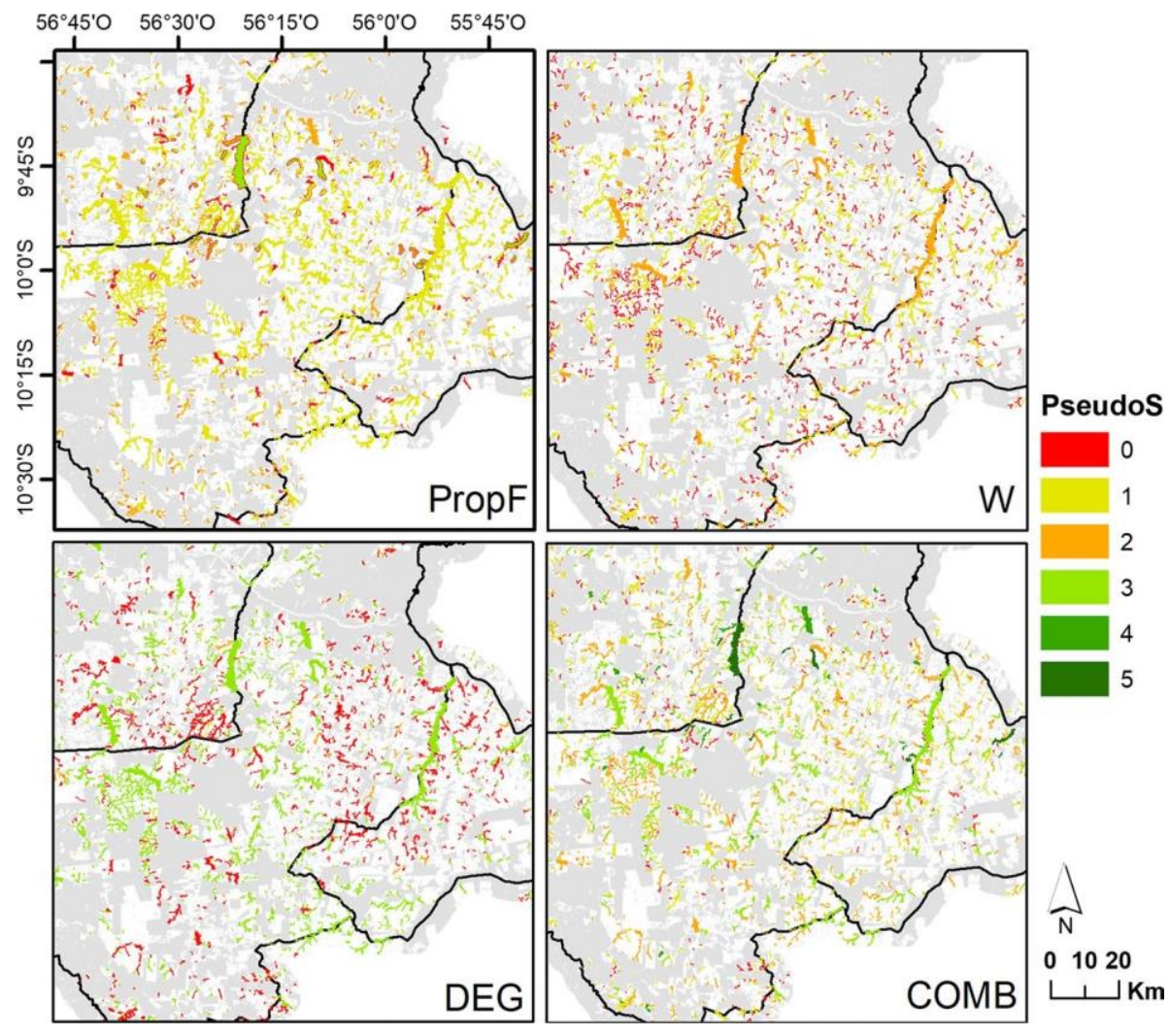

Fig. 5 Heatmaps indicating the pseudo-species-richness (pseudo-S) resulting from the sum of binary maps for all species that responded to patch structure, measured as riparian strip width (W); the total proportion of surrounding forest within a 1-km buffer around each patch (FP); and/or riparian forest quality, measured as the mean proportion of degraded forest within a 50-m buffer around each sampling point (DEG). Binary maps were generated for each species based on the classification of their estimated occupancy probabilities ( $\Psi=0.70)$ and summed across all riparian patches. In the fourth panel, a general map considering the combined occupancy probability in response to all variables together is also presented. Dark line indicates the boundaries of the three municipal counties comprising the study area (Alta Floresta at the centre

However, the ocelot, as a medium-sized predator, may benefit from intermediate levels of habitat fragmentation that affect larger top-predators, by undergoing meso-predator release (Terborgh 1974).

Especially for strict forest specialist organisms, the amount and isolation of riparian forest could predict the degree to which these groups come into contact with anthropogenic disturbances, by either traversing wide gaps of open-habitat matrix, or being subjected to higher levels of edge-mediated disturbance while using riparian landscape connectors. All forest specialists that rarely venture into cattle pastures, such as white-lipped peccary, agouti, tayra, and coati, responded to one or more of the occupancy predictors, while two species most tolerant of open habitat (nine-banded armadillo and capybara) did not. This indicates that degree of habitat specificity and forest dependency define behavioural tolerance to anthropogenic land uses and may be better predictors of responses to habitat loss and fragmentation than other specific eco-morphological traits (Lidicker 1999; Parry et al. 2007). A species sensitivity to habitat fragmentation could thus be better predicted if the 
degree of a priori habitat specificity to anthropogenic disturbance can be taken into account (Henle et al. 2004).

Forest degradation was one of the most important overall determinants of mammal occupancy probability. Four of the ten species considered here exhibited negative responses to forest degradation at the patch- and/or the CT-scale, as measured by the spectral signature of secondary/degraded forests, which reveals clear changes in canopy structure (Gerwing 2002). Most riparian strips at the regional scale were also unsuitable in terms of degradation for high levels of mammal occupancy probability (Fig. 5, Table 4). This is an important policy issue, since Brazilian forest legislation provides no legally mandated guidelines concerning forest habitat quality and integrity within riparian APPs, which can consist of either primary or secondary forests at any stage of regeneration. In the northern state of Mato Grosso, where this study took place, most forest remnants have been severely exposed to anthropogenic impacts, including mechanized logging, wildfires, cattle overgrazing, illegal mining, and hunting (Gerwing 2002; Peres and Michalski 2006; Broadbent et al. 2008). Mapping forest degradation is far less straightforward than mapping deforestation, yet the former has largely overtaken the latter in recent years at least in Brazilian Amazonia (Souza et al. 2013). Recent changes to the Brazilian Forest Code (Law number 12651/2012) have relaxed minimum enforceable requirements for forest restoration by providing legal amnesty to any private landholding that had been previously shown to be below compliance with environmental law. These lenient legislative changes have stimulated an increase in both deforestation and forest degradation throughout the Brazilian Amazon (Fonseca et al. 2015). As a consequence, a 323\% increase in the rate of forest degradation within 12 months was estimated in November 2014 for all nine states across the entire Amazon region, nearly half of which (49\%) affected forest remnants in Mato Grosso (Fonseca et al. 2015).

Mauritia palm aggregations provide a food resource for a number of rodents and ungulates such as the tapirs (T. terrestris), white-lipped peccaries (Tayassu pecari), pacas (Cuniculus paca), and agoutis (D. leporina) (Beck 2006; Endress et al. 2013). As such, we expected a positive effect of Mauritia abundance on occupancy of some of these species. If this were the case, we also expected that carnivore occupancy probability would be higher in these areas due to augmented local herbivore prey. However, palm density had a negative effect on the occupancy patterns of both tayra (E. barbara) and lowland paca $(C$. paca), and no effect on other species. This counterintuitive result (see Zimbres et al. 2017) is likely related to the fact that forest formations associated to Mauritia palms (veredas) are currently highly deforested in the landscape, which may be counter-acting any trophic benefits. Landowners are legally required to set aside a 50-m buffer zone around these palm swamps as a Permanent Protection Area (APP), but since they occupy heavily waterlogged soils, and lack a clearly defined water course from which to measure a protection buffer, most landholders simply remove the forest around them, often well below the minimum legally permitted limits. Vereda remnants are thus entirely waterlogged strips of forest, since the margins of these palm swamps have been mostly cleared, and some forest vertebrate species may subsequently avoid them. This is particularly relevant for pacas, since Mauritia fruits are a preferred resource for this species (Mendieta-Aguilar et al. 2015). The high levels of clear-cuts of palm veredas in the study region thus not only erodes the potential use and landscape connectivity of these riparian zones as, but also suppresses access to an important forest resource.

Another indicator of poor habitat quality, although undetectable by remote-sensing images and uncorrelated with habitat degradation variables, is cattle intrusion into riparian forests, which negatively affected agouti occupancy. Cattle access to riparian zones, 
typically to seek a water source, may affect species occupancy via the detrimental effect of domestic herbivores on understorey vegetation structure through both overgrazing and excessive trampling (Armour et al. 1991; Martin and McIntyre 2007). This can affect the availability of preferred food resources, and their presence may also inhibit animal activity within these patches. A management strategy to prevent riparian forest degradation by cattle is to build fences along the remnant edges, which can be beneficial in two ways: by excluding cattle and by protecting riparian patches against logging activities. Fences can protect against forest degradation, and thereby promote forest remnant value as either habitat or landscape connectors, but may hinder inter-patch movements by some large-bodied species (e.g. tapir, white-lipped peccarise) across the matrix. Fence building, for instance, by installing barbed wire above a certain height only, may prevent cattle access while counter-acting this potential negative impact on native fauna. This strategy has already been proposed and implemented in the region and elsewhere in the country (e.g. Richards et al. 2015), with municipal-scale efforts to provide material and technical support to fence and restore headwater and riparian patches. Such actions, if properly integrated at regional scales could have a huge beneficial impact on the overall quality of riparian forests in fragmented landscapes.

One caveat of this study is that all patches connected by riparian remnants were assumed to play a similar role as source patches, for which we failed to assess differences in baseline occupancy patterns. This may be important wherever riparian forest strips serve as landscape connectors rather than permanent territories in the landscape. However, the lack of a patch size effect for forest sources on the occupancy probabilities of riparian strips suggests that this does not play a decisive role at the present level of deforestation. Distance also did not influence the occupancy of most species (except for T. pecari, for which the observed effect was unreliable and disregarded, as explained in the Results). This pattern corroborates the notion that most study species can either disperse across matrix gap areas or travel great distances along forest strips, depending on the degree of landscape or patch structural integrity, and the organismal scale of perception (Ricketts 2001). Therefore, our results show that these riparian forest strips have the potential to function as either landscape connectors or habitat sustaining year-round home ranges, thereby forming an important element to manage fragmented landscapes.

Although the study landscape still retains a high level of structural connectivity, functional connectivity was generally low, even though several species are known to use or cross degraded cattle pastures (Michalski and Peres 2007). The landscape as whole presented a low proportion of suitable patches for species that responded to forest degradation (at a conservative threshold of $\Psi=0.70$ ). Coatis and collared peccaries were shown to require large patch widths (>220 m). However, both the previous and current environmental legislation concerning the width of riparian APPs are extremely lenient, with current minimum legal requirements ranging from a forest strip as narrow as $5 \mathrm{~m}$ either side of all perennial streams in small landholdings $(<100 \mathrm{ha})$ to $30 \mathrm{~m}$ in large landholdings (> $1000 \mathrm{ha}$ ) on either side of streams narrower than $15 \mathrm{~m}$, which comprise the vast majority of streams and rivers across the study landscape. Effectively, the current legislation simply fails to address the ecological requirements of terrestrial forest vertebrates that would ensure a landscape mosaic in which most species still retain a high probability of effectively dispersing through the landscape, if not surviving within the remaining habitat and associated dispersal conduits.

Similar patterns have been observed for other vertebrate taxa, for which the width of riparian habitat set-aside required to maintain a species composition and abundance comparable to the original baseline far exceeds what was legally prescribed by even 
the more demanding previous Forest Code (Laurance and Gascon 1997; Lees and Peres 2008; De Fraga et al. 2011; Bueno et al. 2012; Garcia et al. 2013). However, several largeholders in our study region already protect a larger amount of riparian forests (mean width in the landscape $=150 \mathrm{~m}$ ) compared to their minimum legal requirements, and around $80 \%$ of all riparian forests in the region were deemed suitable for coatis, which responded to remnant width. This may derive from the fact that many landholders select riparian zones to set-aside both their required APPs and the landholding's Reserva Legal, a forest reserve set-aside also required by the Forest Code (which in Amazonia was historically prescribed at $80 \%$ of the landholding size). This may be a positive strategy in maintaining sufficiently wide riparian strips across the landscape, but, on the other hand, may increase forest isolation and decrease habitat complementarity (sensu Dunning et al. 1992), since fewer upland forest patches will be set aside within landholdings. This may be significant for some species, for which increasing isolation of the riparian forest in the surrounding landscape can affect the functional potential of these patches as habitat or connectors, even if they are adequately wide and relatively intact.

Individual modelling of the effects of habitat structure on occupancy combined with the high idiosyncrasy observed across species cannot provide general rules concerning species' ecological sensitivity to disturbance and functional connectivity to be applied to a wide range of conditions and regions. However, this approach can identify which species are most sensitive to different contexts of landscape structure, as well as the best management strategies that address multiple threat factors at the same time, such as cattle overgrazing. This type of information is relevant at subnational scales, because municipal counties are ultimately the scale at which management decisions are implemented (Gardner et al. 2013). Landholding-level management solutions, beyond safeguarding legal compliance, should include both curbing the local-scale agents of degradation, and/or actively catalyse restoration. Ultimately, enhancing biodiversity persistence in fragmented landscapes will depend on a concerted regional effort to implement management strategies beyond the scale of individual properties and beyond safeguarding legal compliance, and translate the available structural connectivity of riparian systems into a functional connectivity network across entire landscapes.

Acknowledgements $\quad$ BZ is grateful to the Brazilian Ministry of Education (CAPES) for funding her PhD studentship in Brazil, as well as providing her with a PDSE studentship (\#99999.002450/2015-01). We thank the University of Brasilia for help in purchasing camera traps, and the University of East Anglia for hosting BZ during a study visit. The Brazilian National Research Council (CNPq) provided a Research Grant (\#306838/2016-8) to RBM. We also thank Rufford Small Grants Foundation (\#12658-1), the National Geographic Society/Waitt Grant (\#W314-14), the IdeaWild Organization, and a CAPES (\#004-2012) and a Global Innovation Initiative (British Council) Grant (GII 001) to CAP for financial support during fieldwork. We are indebted to all private landowners for granting access to their properties.

\section{Compliance with ethical standards}

Conflict of interest The authors declare that they have no conflict of interest.

Disclosure This study is funded by the Rufford Small Grants Foundation (\#12658-1), the National Geographic Society/Waitt Grant (\#W314-14), the IdeaWild Organization, the Brazilian National Research Council (CNPq; Grant \#306392/2013-5 provided to RBM), the Brazilian Ministry of Education (CAPES; Grant \#004-2012 provided to CAP, and BZ's studentship), and the Global Innovation Initiative (British Council; Grant provided to $\mathrm{CAP}$ ). 


\section{References}

Armour CL, Duff DA, Elmore W (1991) The effects of livestock grazing on riparian and stream ecosystems. Fisheries 16:7-12

Beck H (2006) A review of peccary-palm interactions and their ecological ramifications across the Neotropics. J Mammal 87:519-530

Beier P, Loe S (1992) In my experience: a checklist for evaluating impacts to wildlife movement corridors. Wildl Soc Bull 20:434-440

Beier P, Noss RF (1998) Do habitat corridors provide connectivity? Conserv Biol 12:1241-1252

Bennett AF, Henein K, Merriam G (1994) Corridor use and the elements of corridor quality: chipmunks and fencerows in a farmland mosaic. Biol Conserv 68:155-165

Broadbent E, Asner G, Keller M, Knapp D, Oliveira P, Silva J (2008) Forest fragmentation and edge effects from deforestation and selective logging in the Brazilian Amazon. Biol Conserv 141:1745-1757

Bueno AS, Bruno RS, Pimentel TP, Sanaiotti TM, Magnusson WE (2012) The width of riparian habitats for understory birds in an Amazonian forest. Ecol Appl 22:722-734

De Fraga R, Lima AP, Magnusson WE (2011) Mesoscale spatial ecology of a tropical snake assemblage: the width of riparian corridors in central Amazonia. Herpetol J 21:51-57

Dunning JB, Danielson BJ, Pulliam HR (1992) Ecological processes that affect populations in complex landscapes. Oikos 65:169-175

Eisenberg JF, Redford KH (1999) Mammals of the neotropics, vol 3. The University of Chicago Press, Chicago

Endress BA, Horn CM, Gilmore MP (2013) Mauritia flexuosa palm swamps: composition, structure and implications for conservation and management. For Ecol Manag 302:346-353

ESRI (2015) ArcGIS desktop: release 10.2.2. Environmental Systems Research Institute, Redlands

Fearnside PM (2005) Deforestation in Brazilian Amazonia: history, rates, and consequences. Conserv Biol 19:680-688

Fonseca A, Justino M, Souza C Jr, Veríssimo A (2015) Deforestation report for the Brazilian Amazon (November 2015). Imazon, Belém

Garcia LC, dos Santos JS, Matsumoto M, Silva TSF, Padovezi A, Sparovek G, Hobbs RJ (2013) Restoration challenges and opportunities for increasing landscape connectivity under the new Brazilian forest act. Nat Conserv 11:181-185

Gardner TA, Ferreira J, Barlow J et al (2013) A social and ecological assessment of tropical land uses at multiple scales: the Sustainable Amazon Network. Philos Trans R Soc B 368:20120166

Gascon C, Lovejoy TE, Bierregaard RO Jr, Malcolm JR, Stouffer PC, Vasconcelos HL, Laurance WF, Zimmerman B, Tocher M, Borges S (1999) Matrix habitat and species richness in tropical forest remnants. Biol Conserv 91:223-229

Gerwing JJ (2002) Degradation of forests through logging and fire in the eastern Brazilian Amazon. For Ecol Manag 157:131-141

Haddad NM (1999) Corridor use predicted from behaviors at habitat boundaries. Am Nat 153:215-227

Haddad NM, Tewksbury JJ (2005) Low-quality habitat corridors as movement conduits for two butterfly species. Ecol Appl 15:250-257

Harrison RL (1992) Toward a theory of inter-refuge corridor design. Conserv Biol 6:293-295

Hawes J, Barlow J, Gardner TA, Peres CA (2008) The value of forest strips for understorey birds in an Amazonian plantation landscape. Biol Conserv 141:2262-2278

Henle K, Davies KF, Kleyer M, Margules C, Settele J (2004) Predictors of species sensitivity to fragmentation. Biodivers Conserv 13:207-251

Hilty JA, Lidicker WZ, Merenlender AM (2006) Corridor ecology: the science and practice of linking landscapes for biodiversity conservation. Island Press, Washington, DC

Hobbs RJ (1992) The role of corridors in conservation: solution or bandwagon? TREE 7:389-392

Kéry M (2010) Introduction to WinBUGS for ecologists: a bayesian approach to regression, ANOVA and related analyses. Academic Press, Cambridge

Laurance WF, Gascon C (1997) How to creatively fragment a landscape. Conserv Biol 11:577-579

Lees AC, Peres CA (2008) Conservation value of remnant riparian forest corridors of varying quality for amazonian birds and mammals. Conserv Biol 22:439-449

Lidicker WZ (1999) Response of mammals to habitat edges: an overview. Landsc Ecol 14:333-343

Lindenmayer DB, Nix HA (1993) Ecological principles for the design of wildlife corridors. Conserv Biol 7:627-630

MacArthur RH, Wilson EO (1967) The theory of island biogeography. Princeton University Press, Princeton

MacKenzie DI, Nichols JD, Lachman GB, Droege S, Royle JA, Langtimm CA (2002) Estimating site occupancy rates when detection probabilities are less than one. Ecology 83:2248-2255 
MacKenzie DI, Nichols JD, Royle JA, Pollock KH, Bailey LL, Hines JE (2006) Occupancy estimation and modeling. Elsevier, Burlington

Martin TG, McIntyre S (2007) Impacts of livestock grazing and tree clearing on birds of woodland and riparian habitats. Conserv Biol 21:504-514

Mendieta-Aguilar G, Pacheco L, Roldán A (2015) Dispersión de semillas de Mauritia flexuosa (Arecaceae) por frugívoros terrestres en Laguna Azul, Beni, Bolivia. Acta Amazon 45:45-56

Michalski F, Peres CA (2007) Disturbance-mediated mammal persistence and abundance-area relationships in Amazonian forest fragments. Conserv Biol 21:1626-1640

Michalski F, Peres CA, Lake IR (2008) Deforestation dynamics in a fragmented region of southern Amazonia: evaluation and future scenarios. Environ Conserv 35:93-103

Naiman RJ, Decamps H, Pollock M (1993) The role of riparian corridors in maintaining regional biodiversity. Ecol Appl 3:209-212

Noss RF (1987) Corridors in real landscapes: a reply to Simberloff and Cox. Conserv Biol 1:159-164

Parry L, Barlow J, Peres CA (2007) Large-vertebrate assemblages of primary and secondary forests in the Brazilian Amazon. J Trop Ecol 23:653-662

Peres CA, Michalski F (2006) Synergistic effects of habitat disturbance and hunting in Amazonian forest fragments. In: Laurance WF, Peres CA (eds) Emerging threats to tropical forests. University of Chicago Press, Chicago, pp 105-127

Preston FW (1962) The canonical distribution of commonness and rarity. Ecology 43(185-215):410-432

Prist PR, Michalski F, Metzger JP (2012) How deforestation pattern in the Amazon influences vertebrate richness and community composition. Landsc Ecol 27:799-812

R Development Core Team (2014) R: a language and environmental for statistical computing. R Foundation for Statistical Computing, Vienna. http://cranr-project.org

Richards RC, Rerolle J, Aronson J, Pereira PH, Gonçalves H, Brancalion PHS (2015) Governing a pioneer program on payment for watershed services: Stakeholder involvement, legal frameworks and early lessons from the Atlantic forest of Brazil. Ecosyst Serv 16:23-32

Ricketts TH (2001) The matrix matters: effective isolation in fragmented landscapes. Am Nat 158:87-99

Royle J, Dorazio R (2008) Hierarchical modeling and inference in ecology: the analysis of data from populations, metapopulations and communities. Academic Press, San Diego, p 444

Saunders DA, Hobbs RJ, Margules CR (1991) Biological consequences of ecosystem fragmentation: a review. Conserv Biol 5:18-32

Sberze M, Cohn-Haft M, Ferraz G (2010) Old growth and secondary forest site occupancy by nocturnal birds in a neotropical landscape. Anim Conserv 13:3-11

Souza CM Jr, Siqueira JV, Sales MH, Fonseca AV, Ribeiro JG, Numata I, Cochrane MA, Barber CP, Roberts DA, Barlow J (2013) Ten-year Landsat classification of deforestation and forest degradation in the Brazilian Amazon. Remote Sensing 5:5493-5513

Sparovek G, Barretto AGDOP, Matsumoto M, Berndes G (2015) Effects of governance on availability of land for agriculture and conservation in Brazil. Environ Sci Technol 49:10285-10293

Taylor PD, Fahrig L, Henein K, Merriam G (1993) Connectivity is a vital element of landscape structure. Oikos 68:571-573

Terborgh J (1974) Preservation of natural diversity: the problem of extinction prone species. Bioscience $24: 715-722$

Tracey JA (2006) Individual-based modeling as a tool for conserving connectivity. In: Crooks KR, Sanjayan M (eds) Connectivity conservation. Cambridge University Press, Cambridge, pp 343-368

Tubelis DP, Lindenmayer DB, Cowling A (2007) The peninsula effect on bird species in native eucalypt forests in a wood production landscape in Australia. J Zool 271:11-18

Uezu A, Metzger JP, Vielliard JME (2005) Effects of structural and functional connectivity and patch size on the abundance of seven Atlantic Forest bird species. Biol Conserv 123:507-519

Umetsu F, Paul Metzger J, Pardini R (2008) Importance of estimating matrix quality for modeling species distribution in complex tropical landscapes: a test with Atlantic forest small mammals. Ecography 31:359-370

Wiens JA (1989) Spatial scaling in ecology. Funct Ecol 3:385-397

Zimbres B, Peres CA, Machado RB (2017) Terrestrial mammal responses to habitat structure and quality of remnant riparian forests in an Amazonian cattle-ranching landscape. Biol Conserv 206:283-292 